\title{
Research on the Optimization of Professional Structure of Newly Established Universities from the perspective of Industrial and Educational Integration

\author{
XIE Qin
}

School of Humanities and Law and Economic Management, Shengli College China University of Petroleum, Dongying, Shandong, China

yiyi0723@126.com

*XIE Qin

Keywords: Industrial and educational integration, Newly established universities, Professional structure.

\begin{abstract}
Newly established universities need to optimize the professional structure from the perspective of integration of production and education. They should eliminate the backwardness major and exploit the advantages of dominant discipline; butt the modern industry, build new specialties, strengthen the new agricultural science, new engineering, new liberal arts and new medicine; establish a characteristic professional college with enterprises and establish professional community with other universities. In order to ensure the optimization and adjustment of the professional structure, the newly established universities should set up a diversified professional construction guidance committee, built a database of talent supply and demand and carry out the professional survey and the new professional inspection .
\end{abstract}

\section{产教融合视阈下新建本科高校专业结构优化研究}

\author{
谢芹 \\ 中国石油大学胜利学院文法与经济管理学院, 东营, 山东, 中国 \\ yiyi0723@126.com \\ *谢芹
}

关键词：产教融合; 新建本科高校; 专业结构

中文摘要. 产教融合视阈下, 新建本科高校优化专业结构要淘汰落后同质专业, 发挥优势学 科的作用; 对接现代产业, 建设新兴专业, 加强新农科、新工科、新文科、新医科建设; 校 企协同建立特色专业学院，校校联合建立专业共同体；开展微专业建设。为保障专业结构的 优化调整, 新建本科高校应该建立多元化的专业建设指导委员会; 校企协同建立人才供需数 据库；开展专业普查及新设专业检查。

\section{1. 引言}

专业结构反映了国家的经济社会发展水平、劳动力分工、产业结构等, 集中地体现了社 会对人才的种类、规格、知识、能力、素质等各个方面的要求。2017年年12月国务院办公厅

《关于深化产教融合的若干意见》中明确提出：推动学科专业建设与产业转型升级相适应, 建立紧密对接产业链、创新链的学科专业体系 ${ }^{[1]}$ 。供给侧改革背景下, 我国社会经济呈现新 的特点, 传统产业不断转型升级, 知识、技术、信息、数据等成为新的生产要素, 战略性新 
兴产业不断出现，成为经济新的经济增长点。基于产教融合以及我国经济新形式、新业态、 新模式的需要, 我国高等教育, 尤其是新建本科高校必须进行专业结构的调整优化, 发展社 会急需的专业，淘汰同质落后专业，以更好地服务国家战略及区域经济。

\section{2. 新建本科高校专业结构现状及存在的问题}

\section{1 新建本科高校专业结构现状}

2.1 .1 各学科呈现增长趋势, 但出现不均衡状态

从我国新建本科高校专业设置的总体趋势来看, 呈现缓慢增长趋势。“十一五”期间, 新建本科高校的新设专业数量先降后升, “十二五” 期间, 新建本科高校新设专业的数量先 是呈现加速增长, 之后再次回落, 但整体处于较高的水平。2000年, 我国新建本科高校的新 设专业数量为 56 个，2005年增长到 856 个，2013年达到 1156 个。与此同时, 不同的学科呈现不 均衡的增长状态, 其中增长幅度最大的是工科类专业, 由 2009 年的 1041 个增加到 2014 年的 1763 个, 增幅达到 $69.4 \%$, 平均每年增加 144 个; 其次是管理类专业, 由 2009 年的 546 个增加到 2014 年的 821 个, 增幅达到 $49.5 \%$ ，平均每年增加 54 个; 而哲学、历史等专业的增幅相对较小 ${ }^{[2] 。}$

2.1 .2 逐步形成了相对合理的专业格局

新建本科高校坚持以经济社会发展需求为导向, 主动服务国家战略, 紧密对接产业链布 局, 深化学科专业结构调整, 逐步形成了以工科、管理、艺术为主的专业格局。2015年, 新 建本科高校专业布点中, 工科类专业的布点最多, 在专业总数中所占比重为 $30.5 \%$; 其次是管 理类专业, 专业数占专业布点总数的比例为 $18 \%$, 艺术类专业数量占比排名第三, 占专业布点 总数的 $13.3 \%$ 。而社会需求量较少的专业哲学布点数量为 0 , 历史学所占比重也较低。

2.1.3 专业建设的社会认可度较高

由于新建本科高校针对社会需求进行专业设置, 所培养的人才在社会上获得了较高的评 价和认可。2015年, 新建本科高校的就业率达到 $89.5 \%$, 高于普通老本科高校 $88.8 \%$ 的就业率 水平。从毕业生的就业去向来看, 新建本科高校 $66.7 \%$ 的毕业生进入企业工作, 所占比重较高。 这两个数据充分说明了新建本科高校的专业建设的社会认可度较高。

\section{2 新建本科高校专业结构存在的问题}

\subsection{1 新设专业所占比重较高}

2015年，338所新建本科高校专业数量达到 9593 个，校均专业数量为 28.4 ，其中新设本科 专业数量达到 4418 个, 占新建高校全部本科专业数量的 $46.1 \%$ 。新建专业所占比重高导致学科 资源分散, 不利于专业内涵建设。造成这一问题的主要原因包括两个方面: 一是一些新建本 科高校在进行专业设置时缺乏足够的调研和论证, 在师资、实验仪器设备、实习基地、图书 资料等各种教学资源尚未到位的情况下就开始招生; 二是部分新建本科高校的定位不明确, 仍然定位为综合型大学, 在专业设置方面追求数量, 忽略了专业特色以及内涵建设。

2.2.2 各高校之间专业同质化严重, 缺乏特色

新建本科高校在新设专业时更加倾向于投入低、办学难度小的文科性专业，例如管理、 艺术等学科, 这导致新建本科高校的专业结构中, 工学所占比重严重低于普通老本科高校、 独立学院、985高校、211高校。2015年, 全国高校本科专业结构中, 工科所占比重为 $31.5 \%$, 而新建本科高校只有 $29.2 \%$; 管理学、文学、艺术学、教育学等投资较小、办学难度相对较低 的专业比重严重高于全国高校平均水平。从专业在校生规模来看, 新建本科高校的专业在校 生规模为 335.5 , 高于全国322.1的水平, 说明新建本科高校的专业招生规模总体偏高。

2.2 .3 专业布局与经济发展的适应性较低

从就业情况来看, 我国新建本科高校的专业结构布局不适应国民经济发展、方式转变和 产业结构调整的需要。2015年新建本科高校在校生最多的20个专业分别是会计学、财务管理、 英语、土木工程、计算机科学与技术、机械设计制造及其自动化、汉语言文学、国际经济与 
贸易、环境设计、电器工程及其自动化、视觉传达设计、市场营销、学前教育、电子信息工 程、法学、音乐学、工商管理、数学与应用数学、金融学、软件工程。其中汉语言文学、法 学、数学与应用数学等专业的就业率低于平均就业率水平。这说明一些新建本科高校的专业 设置仍然沿用传统的以学科自身内在逻辑为依据, 缺乏对社会经济发展的考虑, 所培养的学 生与社会需求不匹配。

\section{3. 新建本科高校专业结构优化策略}

产教融合视阈下，新建本科高校必须进一步优化专业结构与布局，以服务国家战略与区 域经济为宗旨, 遵循需求导向、前瞻性原则、宏观调控以及资源整合等原则, 根据国家及区 域经济发展需要, 结合高校自身的定位、发展特色、教学资源、专业结构现状等因素, 进行 专业结构的优化升级。

\section{1 淘汰落后同质专业, 发挥优势学科作用}

\section{1 .1 淘汰落后同质专业}

落后同质专业是指社会需求量少，就业率较低或转出率较高的专业。对落后同质专业的 调整需要从两个方面着手: 一是对高校内部的同质专业进行合并整合, 优化学科布局, 明确 学科建设的主体和责任。高校要注意在调整优化过程中需要逐一与学科建设单位进行对话, 聘请相关专家对各个专业进行评议, 分区域、分层次地提交专家咨询组进行讨论, 逐一提出 优化和调整思路, 经学术委员会辩论通过之后, 再进行实际的执行。二是结合区域经济发展 现状, 确定现在及未来需求量逐渐减少的专业。对于连续多年就业率较低, 又缺乏特色的问 题专业采取逐渐缩减直至淘汰策略。

3.1 .2 发挥优势学科的作用, 形成特色专业

新建本科高校的专业结构调整与优化需要依托原有优势专业, 发展急需专业。对于优势 学科, 新建本科高校主要采取两个方面的措施: 首先, 进一步巩固和强化优势学科的优势, 形成专业尖峰。由于优势学科专业已经积累了一定的教学经验和丰富的资源, 因此, 新建本 科高校应该采取措施进一步向高端、前沿的专业方向发展, 尤其是结合地方经济发展需求, 实现自主创新, 引领行业的发展, 为区域或行业的未来发展提供人才保障。其次, 注意优势 专业与新建专业的协调发展。优势学科专业的发展需要一个较长的过程, 同时也存在着从萌 芽、成长、成熟到衰退的过程。新建本科高校必须注意适度拓展专业适应面, 借助优势专业, 发展交叉专业, 探索新的专业方向, 在跨学科的交叉、融合过程中探索形成新的优势和特色。

\section{2 对接现代产业, 建设新兴专业}

产教融合视阈下, 新建本科高校需要结合我国现代产业发展的需求, 加快经济发展急需 的新兴交叉学科建设, 通过专业升级、专业改造等方式形成面向现代产业的专业集群。

3.2.1 对接现代农业要求, 加强新农科建设

随着信息化的发展以及农业装备制造业的发展, 现代农业的发展将成为必然。未来我国 农业发展的重点包括以下几个方面: 调整农业结构, 促进农业与其它产业的融合, 发展生态 友好型农业, 提升农业技术装备制造业的水平, 推进农业信息化建设。具有农学优势的新建 本科高校应该加快加强新农科建设, 积极发展农业应用学科以及农业交叉学科, 例如经济管 理与农业交叉的学科, 信息化与农业交叉的学科, 机械设计与农业交叉的学科等。与此同时, 结合当地农业的特点, 培养能够综合运用相关专业知识解决区域农业发展问题的创新型、复 合型、应用型农业人才。

3.2 .2 对接战略性新兴产业, 加快新工科建设

近几年, 随着产业结构的转型升级, 我国战略性新兴产业快速发展, 尤其是我国政府提 出以创新、壮大、引领为核心, 紧密结合 “中国制造 2025 ” 战略实施, 坚持创新发展战略, 
促进了我国节能环保、新一代信息技术、生物、高端装备制造业、新能源等产业的发展 ${ }^{[3]}$ 。 新建本科高校要服务国家战略, 服务区域经济发展, 必须对接战略性新兴产业, 加强新工科 建设。新建本科高校要充分利用新工科建设的契机, 对接战略性新兴产业, 对原有的工科专 业进行转型升级, 发展新兴学科。新建本科高校要加强先进制造以及基础制造相关的专业建 设, 培养高端装备制造业相关的应用型人才; 加强工程专业认证, 提升工科专业的水平, 培 养急需的工程技术人才; 打破专业及学科限制, 发展物联网、大数据、云计算等学科的建设, 服务社会大数据战略的发展。

3.2.3 对接第三产业, 加强新文科、新医科建设

随着产业结构的优化升级，我国第三产业的比重不断提升，对现代服务业相关的人才需 求量不断增加, 比如文化创意、精品旅游、现代金融等方面的人才需求数量将会不断增加; 与此同时, 对第三产业人才相关专业的人才质量要求也不断提升。新建本科高校要对接区域 第三产业的需求, 加强文理交叉学科建设, 培养具有创意意识, 具有文理综合能力的应用人 才。具体来说就是要进一步加强生产性和生活性服务相关的专业建设, 例如电子商务、现代 物流、金融、法律、旅游等相关的专业建设; 适应现代医疗服务业发展要求, 积极培养儿科、 全科等医学人才, 在医疗资源短缺的地区, 有条件的高校要开设儿科本科专业建设。

\section{3 多元协同, 开展专业建设}

\subsection{1 校企协同，共建产业学院}

产教融合视阈下，为更好地服务区域经济，新建本科高校可以加强与行业企业的合作， 依托企业优势资源在校内共建特色产业学院。特色产业学院是指以资源共享与合作共赢为目 标, 依托高校建立的具有健全的独立运行机制, 服务于某个行业企业的新型办学机构 ${ }^{[4]}$ 。产 业学院具有如下特征: 从设立本质来看, 产业学院是以学科或专业为载体建立的办学机构; 从设立目标来看, 产业学院的设立是为了实现校企资源共享, 合作共赢; 从服务对象来看, 服务对象明确, 即特定的行业或企业; 从合作主体来看, 与区域内主导产业的领军企业, 也 可以是政府、行业协会等合作; 从运行机制来看, 产业学院具有独立的运行机制, 与高校建 立有契约关系，其经费主要来自于母体高校、政府以及合作的行业企业等。

\subsection{2 校校联合建立专业共同体}

专业共同体是指在一个区域内（或一个省），依托 “一流专业”建立区域内的高校专业 共同体, 开展课程互选, 教师互派, 学生互换, 学分互认等, 实质性促进优质教育资源的共 建共享, 协同深化教学改革, 共同进行专业建设。新建本科高校由于教学资源、教学经费、 师资力量等方面的欠缺, 可能无法开设区域内急需的新专业, 因此可以借助其他高校的资源 培养区域内行业企业所需要的人才, 解决人才供给与需求的不平衡的难题。专业共同体可以 实现资源共享, 提升人才培养的规模效益, 促进新专业的建设。专业共同体建设的内容主要 包括: 课程公选、教师互派、学生互换、学分互认等。课程互选是指高校学生能够选择专业 共同体内其他高校的相关课程进行学习, 课程互选可以通过实地上课也可以通过网络授课的 方式来实现; 教师互派是指高校内的教师能够到其他高校进行讲课; 学生互换是指专业共同 体内的学生能够到其他高校进行学习, 通过学生互换主要能够解决实习、实践等教学的要求; 学分互认是指专业共同体内的高校互相承认学分, 对于学生在其它高校所修学分认可。

\section{4 实施微专业建设}

微专业是指以企业项目为依据, 以培养核心技能为目标, 由少数核心课程组建而成立的 专业体系的学习, 使得学生能够达到某个专业领域的学习技能要求, 以满足企业项目开发对 人才的需求 ${ }^{[5]}$ 。产教融合视阈下, 新建本科高校可以通过微专业建设, 更好地服务区域经济, 提高专业结构调整的灵活性, 在一定程度上改变专业结构调整滞后性的状态。新建本科高校 实施微专业建设能够使学生能够快速地掌握企业项目开发所需要的专业核心能力; 能够对企 
业人员进行 “项目驱动培训” ，提升企业人员的相关专业能力; 能够为新专业的发展奠定基 础，当“微专业” 发展到一定规模之后，可以将 “微专业”升级为新的专业。

微专业包括四个方面的特点: 一是将专业的核心课程进行有机融合, 以企业项目需求为 导向, 以课程教学模式改革为核心; 二是高校与行业企业共同参与教学, 对于能力培养要求、 所要开设的课程、课程内容及课程大纲的设置、对学生的评价等全程都需要校企协同进行; 三是理论学习与实习实践无缝对接, 学生在完成部分理论课程的学习之后能够直接进入企业 进行实习实践, 促使所学理论成功转化为实际能力; 四是实习实践与就业无缝对接, 学生完 成相应的课程以及规定的实习实训之后, 符合企业考核标准的, 就能够直接进入企业正式工 作，实现实习实践与职业的无缝衔接。

新建本科高校微专业构建需要遵循以下流程: 首先, 企业根据自身的需求与高校进行合 作意向洽谈, 选拔人才, 确定合作的内容以及相关的责任划分, 签订合作协议; 其次, 高校 与行业企业共同确定所要培养的能力及对应的课程体系, 根据企业需求, 校企协同制定教学 内容; 再次, 校企共同进行课程教学的实施, 实施过程中, 部分课程内容由高校教师承担, 涉及到行业企业相关的课程要由企业专家承担, 实践课程要由校企双方的导师进行共同指导; 最后, 及时对学生学习情况进行共同的评价考核, 以确定所培养学生的能力水平, 合格的学 生在实习结束后直接进入企业就业。

\section{4. 新建本科高校专业结构优化的保障措施}

\section{1 建立多元化的专业建设指导委员会}

新建本科高校在自主设置目录内的非国家控制布点时, 采取直接备案制, 意味着高校有 了更高的自主性和决策风险。因此, 产教融合视阈下, 新建本科高校需要建立多元化的专业 建设指导委员会, 加强申报专业的审核, 确保专业符合社会经济发展要求, 符合高校自身的 定位。专业建设指导委员会应该由企业人员、行业人员、学科专业的相关专家以及高校内部 人员构成。专业建设指导委员会的任务在于对所要开设的新专业进行专业论证, 具体来说包 括: 对所要开设的专业进行社会需求的分析预测, 尤其是要根据行业企业对相关人才需求的 增长变化情况, 判断预测几年之后的人才需求, 而不是只分析目前社会经济发展对人才的需 求情况; 对所要开设专业的教学计划、教学方案的合理性进行审核, 从而确保新设专业的教 学质量; 对高校内部相关的教学资源情况进行评估, 以保障所开设专业的师资力量、教学资 源, 对高校内部的学科专业结构进行论证分析, 确保所开设专业能够符合高校专业结构的特 征, 能够形成专业集群。通过高校内部的审核, 能够决定新设专业是否要向上级申报。

\section{2 校企协同建立人才供需数据库}

产教融合视阈下, 新建本科高校进行专业结构的优化调整, 需要消除与企业信息不对称 的情况。高校与行业企业协同建立人才供需数据库, 是进行专业调整的必要措施。首先, 产 教融合视阈下, 行业协会要充分发挥作用, 做好各专业人才的需求统计及预测分析。行业协 会要对本区域内行业对各专业人才的需求情况进行统计分析, 以及各人才在行业内企业的分 布情况进行分析以及预测, 从而确定各企业对人才的需求量。高校根据未来人才需求情况进 行专业结构的调整与优化。其次, 高校建立年报制度, 统计本校各专业的人才需求情况以及 就业情况, 对于就业率较低的专业要采取一定措施进行限制, 对于需求量大而本校缺少的专 业进行设置与发展。

\section{3 开展专业普查及新设专业检查}

为提高专业对区域经济发展的适应性, 教育主管部门要对各高校专业进行普查以及新设 专业开展检查制度, 以确保人才培养质量。首先, 教育主管部门要对专业的课程、教材、师 资、实践等基本办学条件进行摸底监测, 精准引导高校加强专业基本建设, 自住人才培养质 
量的 “底”。其次, 开展新专业检查。教育主管部门要对高校新设专业开展检查工作，对新 设专业的教学质量、教学资源等进行持续的监测调查, 以确保新建本科高校按照备案要求进 行专业建设及人才培养, 对建设成效不明显的要求限期进行整改, 整改仍然不合格者予以撤 销。

\section{5. 结束语}

我国新建本科高校的专业结构调整取得了一定的成效, 各学科呈现增长趋势, 但出现不 均衡状态; 逐步形成了相对合理的专业格局; 专业建设的社会认可度较高; 形成了一批具有 特色的品牌专业。但其专业结构也存在一些问题: 新设专业所占比重较高; 各高校之间专业 同质化严重, 缺乏特色; 专业布局与经济发展的适应性较低。产教融合视阈下, 新建本科高 校优化专业结构要淘汰落后同质专业, 发挥优势学科作用; 对接现代产业, 建设新兴专业, 加强新农科、新工科、新文科、新医科等学科建设; 校企协同, 建立特色专业学院, 校校联 合建立专业共同体; 开展微专业建设。为保障专业结构的优化调整, 建立多元化的专业建设 指导委员会；校企协同建立人才供需数据库；开展专业普查及新设专业检查制度。

\section{致谢}

本文为山东省教育科学十三五规划课题《生态位视阈下黄河三角洲高校服务区域经济与 社会发展的实证研究》 (编号: YC2017098) 的阶段性成果之一。在此感谢山东省教育科学 规划办提供的支持。同时感谢各位学者所做的相关研究, 为本文的研究提供了思路和借鉴。

\section{References}

[1] General Office of the State Council Some opinions on deepening the integration of production andeducation[EB/OL].[2017-12-19].http://www.moe.edu.cn/jyb_xxgk/moe_1777/moe_1778/2 01712/t20171219_321953.html.

[2] Higher education assessment center.Report on the quality of education in newly established universities [R]. Beijing: Educational Science Press.pp.21,2017.

[3] State Council Announcement on the development plan of the national strategic emerging industries in

Five-Year.[EB/OL].[2016-12-19].http://www.gov.cn/zhengce/content/2016-12/19/content_515 0090.htm

[4] ZHU Weihong and PENG Yunfei.Research on the construction of industrial college in local undergraduate colleges and universities under the background of new engineering,Journal of Higher Education Management,vol 12,pp. 30-37,2018.

[5] ZHANG Zhiqiang and Zhang Hong.Research on the core curriculum system of "micro specialty" degree of software engineering based on Local Universities,Education modernization,vol 5,PP.116-118,2018. 